\title{
Long-term outcome in treated combined methylmalonic acidemia and homocystinemia
}

Hans C. Andersson, MD, Michael Marble, MD, and Emmanuel Shapira, $M D, P h D^{*}$

\begin{abstract}
Purpose: To describe the clinical and biochemical features and long-term outcome of a cohort of eight patients with methylmalonic acidemia and homocystinuria (cblC). Methods: Documentation of clinical features at birth and longitudinal follow-up of the biochemical and clinical response to treatment with daily oral carnitine and intramuscular hydroxocobalamin observed during continuous follow-up for an average of 5.7 years. Results: Our patients had an increased incidence of congenital malformations including microcephaly $(<5 \%)$ at birth $(2$ of 8$)$, congenital heart disease ( 2 of 8 ), dysmorphic facial features ( 1 of 8 ), and thyroglossal duct cyst ( 1 of 8 ). Postnatal hydrocephalus ( 2 of 8 ) and hip dislocation caused by ligament laxity ( 1 of 8 ) were also noted. One patient had profound visual impairment before 6 months of age secondary to cblC retinopathy, and two patients had abnormal retinal pigmentation with normal visual function. All patients presented with poor growth, feeding problems, and/or seizures. No patients had acute acidotic crises before or after treatment. All patients had dramatic reduction of plasma free homocystine and urine methylmalonic acid excretion after initiation of therapy with carnitine, intramuscular (IM) hydroxocobalamin $(\mathrm{OHcbl})$ and, in two cases, oral betaine. Growth was significantly improved in most cases after the initiation of therapy, and microcephaly was resolved in one patient. All patients were developmentally delayed regardless of age of treatment onset, although two patients had relatively mild developmental delay. Conclusion: cblC patients may have an increased incidence of congenital malformations suggesting prenatal effects of abnormal cbl metabolism. Treatment with IM OHcbl and carnitine successfully corrects the biochemical abnormalities and improves growth. Developmental delay of variable severity is always present regardless of age at diagnosis or treatment onset. Genetics in Medicine, 1999:1(4):146-150.
\end{abstract}

Key words: cobalamin, cb/C, methylmalonic acidemia, homocystinuria, outcome

\section{INTRODUCTION}

Combined methylmalonic acidemia (MMA) and homocystinuria occurs as an inborn error of metabolism believed to be caused by an unknown defect in cobalamin synthesis. ${ }^{1-3}$ The deficiency of the processed form of cobalamin results in deficient activity of two cobalamin-dependent enzymes, methylmalonyl CoA mutase, and $\mathrm{N}^{5}$-methytetrahydrofolate:homocysteine methyltransferase. Patients with the coincidence of these two metabolic aberrations present with failure to thrive, developmental delay, retinopathy and, occasionally, hematologic aberrations. The disease, referred to as cblC disease based on its complementation class, is clinically variable, and prognosis has not been established.

Although more than 20 individual cases of cblC patients have been reported, no cohort of patients and their features has ever been described. Rosenblatt et al. ${ }^{3}$ has described the clinical features of 50 patients whose samples were referred for biochemical analysis by survey of their physicians. We describe the clinical

\footnotetext{
Hayward Genetics Center, Human Genetics Program. Tulane University' School of Medicine; New Orleans, Louisiana

Hans C. Andersson, MD, Hunan Genetics Program SL-31, Hayward Genetics Center, 1430 Tulane Avenue, New Orleans, LA 70112; E-mail: handers@tmipop.tmc.tulante.edu

* deceased

Submitted for consideration December 30, 1998; accepted for publication February 26, 1999.
}

and biochemical features of eight cblC patients who were treated by the authors for an average of 5.7 years. This cohort documents the efficacy of biochemical treatment and the long-term outcome in this disorder.

\section{METHODS}

Eight patients in whom we established the diagnosis of cblC disease were referred to the Tulane Human Genetics Program from 1986 to 1997 for evaluation of failure to thrive, feeding problems, and/or seizures. The patients were followed by our program for an average of 5.7 years (1.9-10.8 years). Medical records of patients born outside of our hospital were obtained for review. Diagnosis was established by: 1) the presence of urinary methylmalonic acid assayed by gas chromatography, with mass spectroscopy analysis in later samples; ${ }^{4} 2$ ) the elevation of plasma free homocystine as determined by HPLC; $;^{4}$ and 3 ) genetic complementation studies of our patients' fibroblasts performed at McGill University (Dr. David Rosenblatt). The normal plasma free homocystine is essentially $0 \mathrm{nmol} / \mathrm{ml}$, and the normal range for urine methylmalonic acid is $0-20 \mathrm{mg} / \mathrm{gm}$ creatinine. Total plasma homocysteine values were not reported because most patients were diagnosed and treated before the establishment of that analysis. In the complementation studies, the patient's cultured fibroblasts were fused with known 
Table 1

Developmental outcome*

\begin{tabular}{|c|c|c|c|c|c|c|c|}
\hline $\begin{array}{c}\text { Age at } \\
\text { Patient No. }\end{array}$ & $\begin{array}{l}\text { Age at } \\
\text { report }(y)\end{array}$ & $\begin{array}{c}\text { Age at } \\
\text { diagnosis (mo) }\end{array}$ & $\begin{array}{c}\text { Age at } \\
\text { devel. test }(y)\end{array}$ & $\begin{array}{l}\text { Deve } \\
\text { fine motor }\end{array}$ & $\begin{array}{l}\text { lopmental quo } \\
\text { gross motor }\end{array}$ & $\begin{array}{l}\text { tient } \\
\text { cognitive }\end{array}$ & Clinical Correlation \\
\hline 1 & 13 & 11 & 5.8 & 0.3 & 0.3 & 0.3 & $\mathrm{CNcbl}$ until $22 \mathrm{mo}$, then $\mathrm{OHcbl}$ \\
\hline 2 & 12 & 3 & 5.8 & 0.3 & 1.0 & 0.5 & congenital microcephaly, FOC $10 \%$ at $6 y$ \\
\hline 3 & 11 & 2 & 4 & 0.8 & 0.8 & 0.8 & $\mathrm{CNcbl}$ until $3 \mathrm{mo}$, then $\mathrm{OHcbl}$, received betaine \\
\hline 4 & 8.3 & 5 & 5.9 & 0.3 & 0.4 & 0.3 & $\begin{array}{l}\text { mild pulmonic stenosis, hydrocephalus shunted at } 6 \\
\text { mo, thyroglossal duct cyst noted at } 4 \mathrm{y} \text {; received betaine }\end{array}$ \\
\hline 5 & 8 & 2 & 0.8 & 0.7 & 0.7 & 0.7 & $\begin{array}{l}\text { VSD, hydrocephalus at } 7 \mathrm{mo} \text {, profoundly delayed after } \\
\text { V-P shunt malfunction at } 13 \text { mo }\end{array}$ \\
\hline 6 & 6.5 & 5 & 4.2 & 0.2 & 0.2 & 0.2 & all growth parameters $<5 \%$ at $5 y$ \\
\hline 7 & 4 & 0.3 & 1.2 & 0.3 & 0.3 & 0.4 & $\begin{array}{l}\text { dysmorphic facial features, ligamentous laxity, bilat hip } \\
\text { dislocation requiring surgery }\end{array}$ \\
\hline 8 & 3.2 & 5 & 2.4 & 0.4 & 0.6 & 0.6 & congenital microcephaly, profound visual impairment \\
\hline
\end{tabular}

"defined as developmental age/chronologic age.

VSD, ventriculoseptal defect.

cobalamin complementation group fibroblasts, using polyethylene glycol, and studied for their ability to incorporate $\left[{ }^{14} \mathrm{C}\right]$ propionate into trichloroacetate-precipitable macromolecules. ${ }^{3}$ The failure to enhance propionate metabolism in known cblC fibroblasts by fusion with the patient's fibroblasts, compared with cocultured but unfused cells, is diagnostic of cblC disease.

All patients were treated with hydroxocobalamin (1mg qd IM), although two patients were initially treated with the same dose of cyanocobalamin for 6 and 85 weeks, respectively, before being switched to hydroxocobalamin. ${ }^{5}$ All patients received oral carnitine supplementation $(50-100 \mathrm{mg} / \mathrm{kg} / \mathrm{d})$. Two patients were treated with betaine $(0.5-1 \mathrm{gm} / \mathrm{d})$ for intermittent homocystinemia. Patients were followed with clinic visits every 3-6 months and, in most cases, biochemical analysis of urine organic acids and plasma amino acids every 6-12 weeks. Carnitine studies were performed in all patients at least yearly while on carnitine supplementation. Developmental evaluations were performed by early intervention services and school programs. These evaluations determined developmental age in gross motor, fine motor, and cognitive abilities. A crude developmental quotient, defined as the developmental age/chronologic age, was used to grossly characterize the patients' development.

\section{RESULTS}

Our cohort demonstrated a relatively high incidence of congenital malformations. Table 1 documents each patient's features and developmental outcome. Two patients had congenital microcephaly (FOC $<5 \%$ ile). Another patient had dysmorphic facial features (cupid bow upper lip, bilateral epicanthal folds) and profound ligament laxity with bilateral hip dislocations. Two other patients had congenital heart disease (pulmonic stenosis, ventriculoseptal defect) not requiring treatment. One patient was noted to have a thyroglossal duct cyst, and two patients developed hydrocephalus at 7 and 8 months of age, respectively, and required ventriculoperitoneal shunting. One patient had profound visual impairment with an abnormal electroretinogram at age 6 months and no detectable visual improvement after 2 years of treatment. Two other patients had abnormal retinal pigmentation without detectable visual impairment. The patients were all Caucasian from southern Louisiana and many were from French Canadian background. There was no known consanguinity.

The age at diagnosis was between 1 week and 11 months, with an average age of 4.8 months. No patient presented with acute acidosis as is seen in other forms of methylmalonic acidemia. Two patients on treatment had multiple transient episodes of vomiting without MMA or acidosis. None of the patients had significant anemia.

Biochemically, all patients presented with dramatically elevated urinary methylmalonic acid and plasma free homocystine. The biochemical response to IM OHcbl treatment (six patients) is shown in Figures 1 and 2; treatment response of the two patients ( 1 and 3 ) initially treated with $\mathrm{CNcbl}$ was previously reported. ${ }^{5} \mathrm{OHcbl}$ and carnitine supplementation was very effective in decreasing the MMA and homocystine in all patients. Urinary methylmalonic acid values fell to and remained less than $150 \mathrm{mg} / \mathrm{gm}$ creatinine, except during intercurrent illness when transient elevation of methylmalonic acid was seen in one patient. Urinary MMA levels rarely dropped less than $50 \mathrm{mg} / \mathrm{gm}$ creatinine. Plasma free homocystine remained less than 3 $\mathrm{nmol} / \mathrm{ml}$, except during intercurrent illness. Plasma carnitine was usually normal in all patients while on carnitine supplementation, but during periods of stress or noncompliance, occasional values of plasma free carnitine were undetectable.

In general, growth of height and weight was at the normal rate with occasional periods of suboptimal growth during treatment (Figures 3 and 4). Only patient 4, who was born with normal growth parameters (height, weight, FOC), had normal postnatal growth. Three patients $(1,2$, and 3$)$ fell below $5 \%$ ile for height, weight, or FOC but achieved catch-up growth into normal percentiles for all parameters after treatment; one of these patients (2) had congenital microcephaly. The growth data 


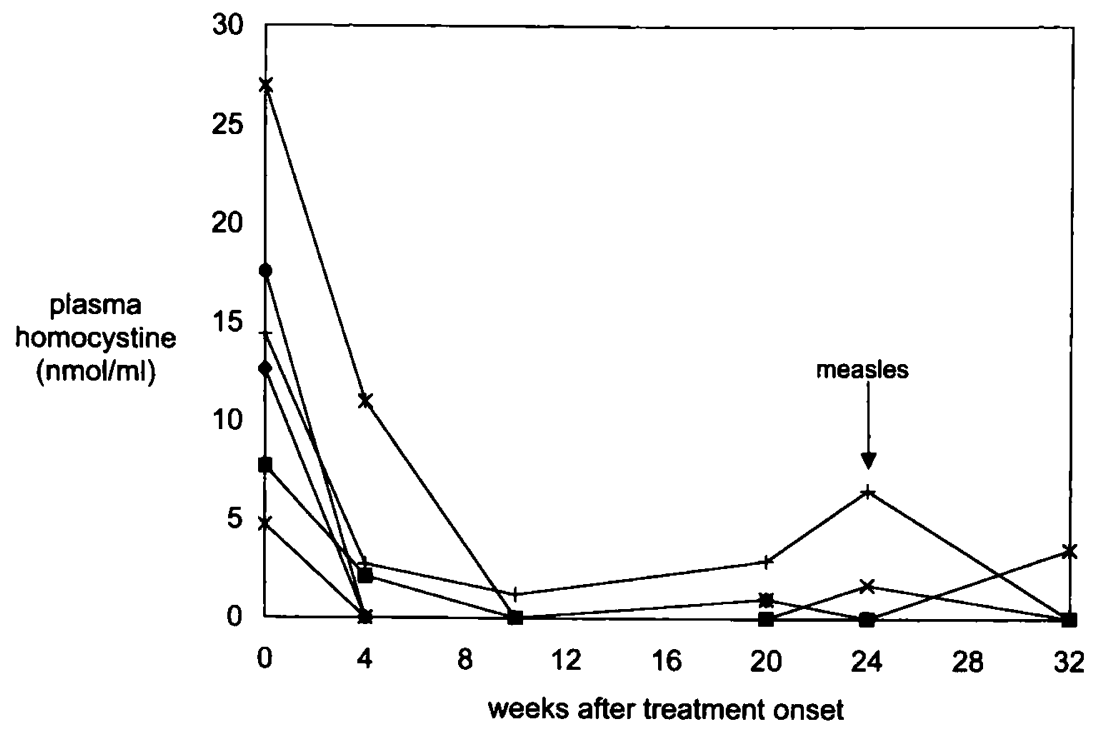

Fig. 1 Plasma free homocystine $(\mathrm{nM} / \mathrm{ml})$ after initiation of $1 \mathrm{M}$ OHcbl treatment. Data for patients 1 and 3 were previously reported. ${ }^{5}$ Key: patient 2 : $\mathbf{W}$; patient 4 : $\mathbf{X}$; patient 5 : $\$$; patient $6: \star$; patient 7 : $\bullet$; patient 8 :

for patient 1 have been previously reported. ${ }^{5}$ Severe microcephaly in patient 5 occurred after a ventriculoperitoneal shunt malformation associated with respiratory arrest.

All patients had developmental delay, but the degree of involvement was highly variable (Table 1). Most patients had global delay, but patient 2 had normal gross motor skills at 5.9 years and only mild cognitive dysfunction. Patient 4 had the best developmental outcome and is presently in regular 5th grade classes with remedial instruction. Patient 6 has profound visual impairment and this may have some direct effect upon her test results for gross motor, fine motor, and cognitive skills. Patient 8 had only mild delay before an acute adverse neurologic event (ventriculoperitoneal shunt malfunction) at 13 months that resulted in severe psychomotor retardation.

\section{DISCUSSION}

The presentation of cblC disease with combined methylmalonic acidemia and homocystinuria, although clinically variable, is unlike either isolated methylmalonic acidemia or homocystinuria. Our eight patients presented with an indolent course of poor feeding, hypotonia and, in one patient, seizures. None of our patients ever had acute acidotic crises characteristic of methylmalonyl CoA mutase deficiency, a more common cause of methylmalonic acidemia. Our patients had an unusually high incidence of congenital malformations, which is characteristic of neither methylmalonyl CoA mutase deficiency nor cystathionine synthase deficiency.

All patients in this report were developmentally delayed. The severity of developmental delay cannot be solely related to age

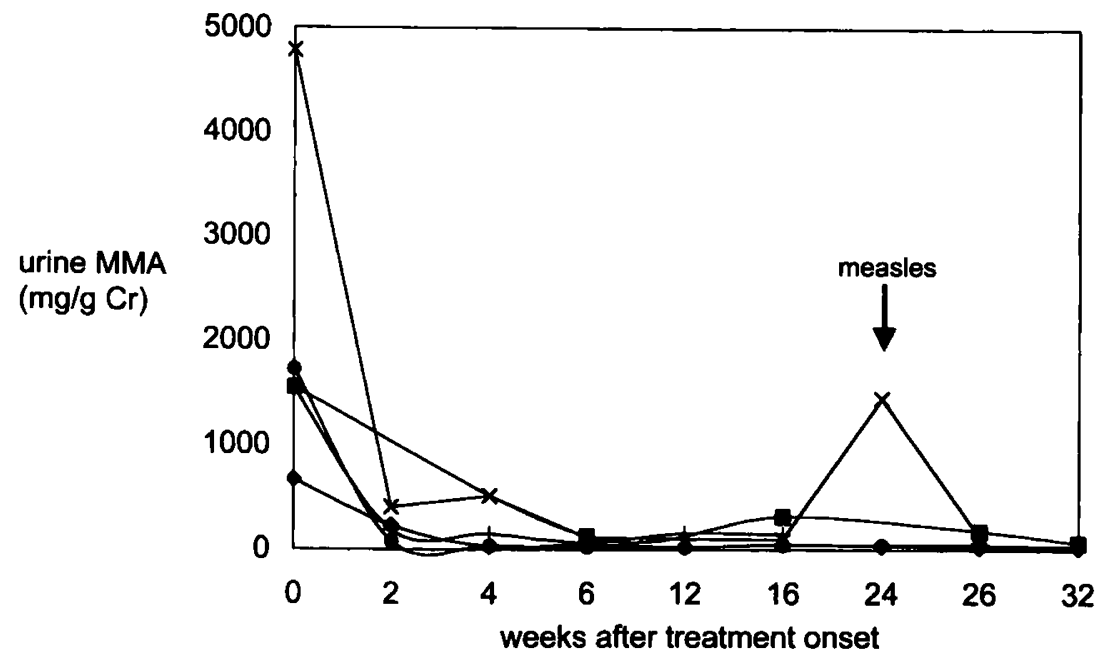

Fig. 2 Urine methylmalonic acid levels after initiation of OHcbl treatment. Data for patients 1 and 3 were previously reported. $^{5}$ 

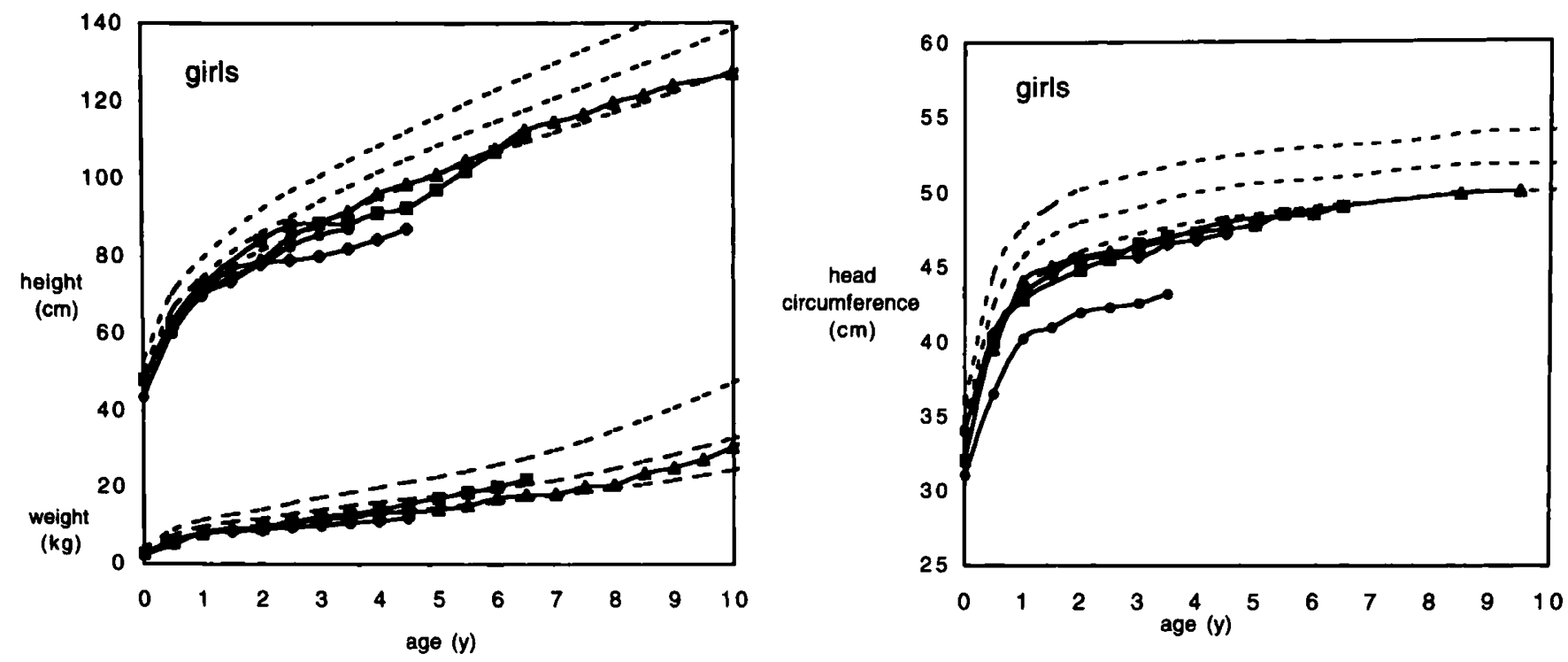

Fig. 3 Height weight and head circumference for girls (patients 2, 3, 7, and 8). Dashed lines give 5\%ile, 50\%ile, and 95\%ile for age-matched controls. Patient 3:

of treatment onset because the earliest treated patient (patient 5) had one of the poorest outcomes. Our two patients with congenital microcephaly without another explanation (patients 2 and 8) suggest prenatal effects on brain development of cblC disease. Additionally, subtle intracranial malformations may have predisposed two other patients ( 5 and 6 ) to develop hydrocephalus at 7 and 8 months of age.

Biochemical control of urinary MMA and plasma free homocystine was relatively easily achieved by IM OHcbl and oral carnitine, with the adjunct of oral betaine in two patients. Significant and long-term reductions of urine MMA less than $150 \mathrm{mg} / \mathrm{gm}$ creatinine and undetectable plasma free homocystine allowed improved growth in all patients. Four of eight patients had normal growth parameters at age 5 to 7 years after three had fallen below $5 \%$ ile for height, weight, and FOC. In the single patient with profound visual impairment, no clear benefit to eyesight was noted either clinically or by repeated electroretinograms after 2 years of treatment.

All patients in this report were diagnosed before 1 year of age. Unlike the patients surveyed in Rosenblatt et al. ${ }^{3}$ in which 13 of 44 early-onset patients died, none of our patients died of their biochemical aberrations. This may be partially explained by prolonged use of $\mathrm{CNcbl}$ or the lack of cofactor therapy in some of the patients who died in their report.
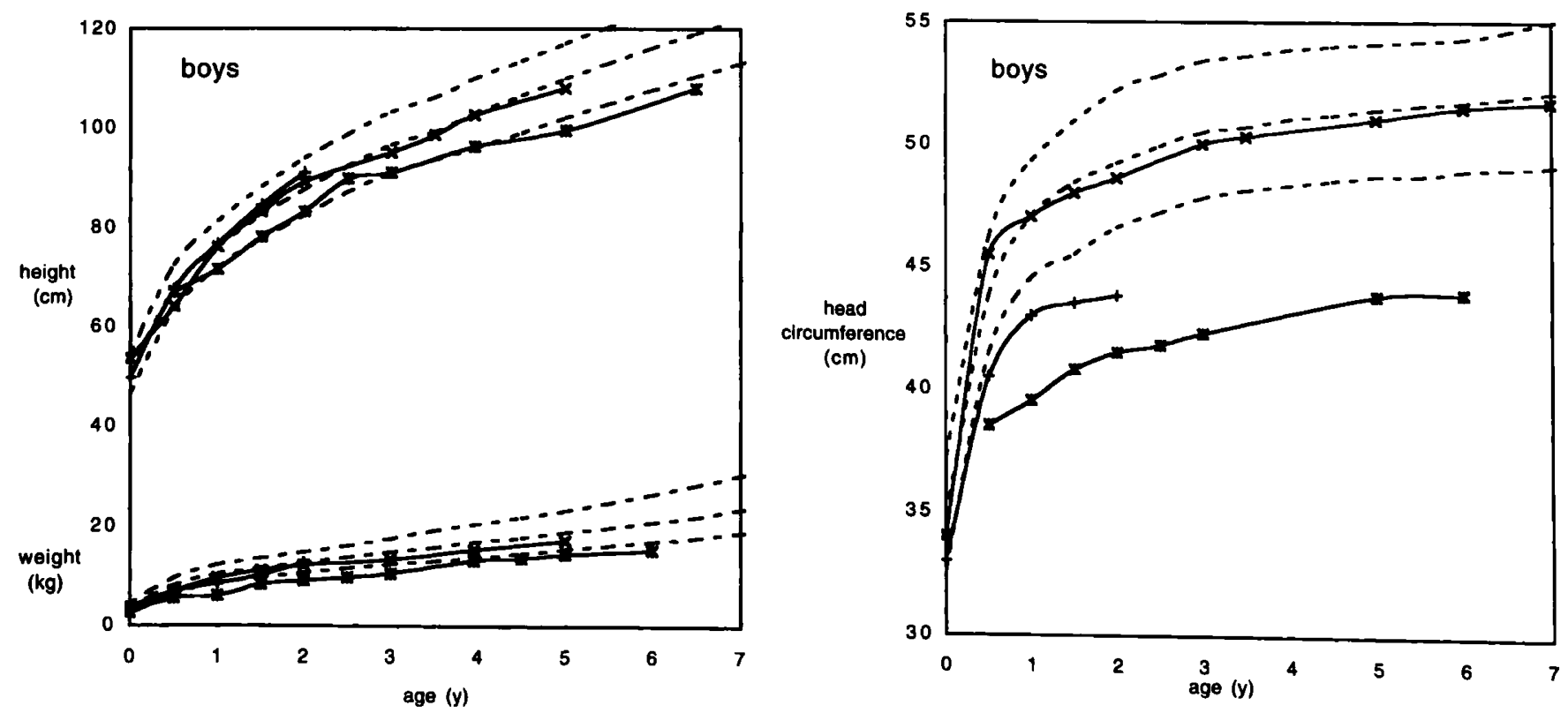
Fig. 4 Height weight and head circumference for boys (patients 4,5, and 6). Dashed lines give 5\%ile, 50\%ile, and 95\%ile for age-matched controls. Data for patient 1 was previously
reported. 
cblC disease is defined biochemically and may be genetically heterogeneous. No single enzymatic deficiency has been identified to explain the deficiency of processed cobalamin that leads to the biochemical abnormalities. Recent data demonstrate reduced activity of a $\beta$-axial-ligand transferase ${ }^{6}$ and mitochondrial NADH-linked aquacobalamin reductase activity ${ }^{7}$ in cblC fibroblasts compared with controls. The possibility that mutations at distinct genetic loci may cause cblC disease will only be resolved once a candidate enzymes or gene(s) is identified.

\section{References}

1. Rosenblatt DS. Inherited disorders of cobalamin metabolism: an overview. In: Besser M, Bhatt R, Bottazzo F, James VHT, Keen H, eds. Advances in Thomas Addison's Diseases. Bristol: Journal of Endocrinology Ltd., 1994:303-313.

2. Fenton W, Rosenberg LE. Inherited disorders of Cobalamin transport and metabolism.
In: Scriver CR, Beaudet AL, Sly WS, Valle D, eds. The Metabolic and Molecular Bases of Inherited Disease, 7th ed. New York: McGraw-Hill, 1995:3129-3149.

3. Rosenblatt DS, Aspler AL, Shevell MI, Pletcher BA, Fenton WA, Seashore MR. Clinical heterogeneity and prognosis in combined methylmalonic aciduria and homocystinuria (cblC). J Inherit Metab Dis 1997;20:528-538.

4. Shapira E. Diagnostic tests for metabolic disorders. In: Shapira E, Blitzer M, Miller J, Africk D, eds. Biochemical Genetics: A Laboratory Manual. New York: Oxford University Press, 1989.

5. Andersson $\mathrm{HC}$, Shapira E. Biochemical and clinical response to $\mathrm{OHcbl}$ vs $\mathrm{CNcbl}$ treatment in combined methylmalonic acidemia/homocystinuria (cblC). J Pediatr 1998;132:121-124.

6. Pezacka EH and Rosenblatt DS. Intracellular metabolism of cobalamin. In: Besser M, Bhatt R, Bottazzo F, James VHT, Keen H, eds. Advances in Thomas Addison's Diseases. Bristol: Journal of Endocrinology Ltd, 1994:315-323.

7. Watanabe F, Saido H, Yamaji R, Miyatake K, Isegawa Y, Ito A, Yubisui T, Rosenblatt DS, Nakano Y. Mitochondrial NADH- or NADPH-linked aquacobalamin reductase activity is low in human skin fibroblasts with defects in synthesis of cobalamin coenzymes. J Nutr 1996;126:2947-2951. 